\title{
Conversion of orange peel to L-galactonic acid in a consolidated process using engineered strains of Aspergillus niger
}

\author{
Joosu Kuivanen ${ }^{1 *}$, Hugo Dantas ${ }^{1}$, Dominik Mojzita ${ }^{1}$, Edgar Mallmann², Alessandra Biz², Nadia Krieger²,
} David Mitchell ${ }^{2}$ and Peter Richard ${ }^{1}$

\begin{abstract}
Citrus processing waste is a leftover from the citrus processing industry and is available in large amounts. Typically, this waste is dried to produce animal feed, but sometimes it is just dumped. Its main component is the peel, which consists mostly of pectin, with D-galacturonic acid as the main monomer. Aspergillus niger is a filamentous fungus that efficiently produces pectinases for the hydrolysis of pectin and uses the resulting D-galacturonic acid and most of the other components of citrus peel for growth. We used engineered A. niger strains that were not able to catabolise D-galacturonic acid, but instead converted it to L-galactonic acid. These strains also produced pectinases for the hydrolysis of pectin and were used for the conversion of pectin in orange peel to L-galactonic acid in a consolidated process. The D-galacturonic acid in the orange peel was converted to L-galactonic acid with a yield close to $90 \%$. Submerged and solid-state fermentation processes were compared.
\end{abstract}

Keywords: Citrus processing waste; Orange peel; Consolidated bioprocessing; L-galactonic acid; D-galacturonic acid; Aspergillus niger

\section{Introduction}

Utilization of agricultural wastes for the production of fuels and chemicals using microbial fermentations is an attractive concept, due to the low costs of the raw material and beneficial environmental aspects. However, the profitability of utilizing agricultural residues can be reduced by logistical costs, if the feedstock is dispersed over a wide area and by the need for pre-treatments before the fermentation. Consequently, the ideal process would utilize an existing logistic chain and a feedstock that does not need extensive pre-treatment. Citrus processing waste (CPW) is an example of such a feedstock: its generation is centralized within a citrus processing plant and, due to low lignin content (Edwards and Doran-Peterson 2012), it does not require extensive pre-treatment.

The current annual world production of citrus fruits is greater than 80 million tonnes, of which oranges constitute about 50 million tonnes (USDA 2013). About 20

\footnotetext{
*Correspondence: joosu.kuivanen@vtt.fi

'VIT Technical Research Centre of Finland, PO Box 1000, 02044 VIT, Espoo, Finland

Full list of author information is available at the end of the article
}

million tonnes of these oranges are used by the orange processing industry (USDA 2013). The production of orange juice generates a large quantity of CPW, with around $44-60 \%$ of the mass of processed orange fruit ending up as CPW (Widmer et al. 2010, López et al. 2010). Thus, approximately 10 million tonnes of wet $\mathrm{CPW}$ is generated annually in the world by the orange processing industry alone.

CPW, in turn, contains mainly peels. These peels are rich in pectin and also contain a significant quantity of Dlimonene. The pectin content in CPW is around $25 \%$ on a dry mass basis, corresponding to about $5 \%$ on a wet mass basis (Pourbafrani et al. 2010). Currently, the markets for pectin and D-limonene consume only a relatively small fraction of the CPW. For example, the world market for pectin, which is used as a gelling agent in the food industry, was estimated as 42000 tonnes per year in 2009 (Staunstrup 2009), whereas the CPW generated annually by the orange processing industry could produce approximately 500000 tonnes of pectin. In other words, over $90 \%$ of the CPW produced by the orange processing industry is in excess of the world pectin market. This excess CPW 
could be used for animal feed. However, this is seldom economic, due to the high energy requirements for the processes of drying and milling that are necessary to transform the CPW into a meal that is appropriate for adding to animal feed (Grohman et al. 2013). As a result, the $\mathrm{CPW}$ is sometimes simply discarded. It is therefore highly desirable to find new ways of converting pectin-rich residues into useful products, following the worldwide trend of using renewable resources to substitute petroleum derivatives.

So far, most attempts to produce higher-value products from $\mathrm{CPW}$ have involved extracting compounds such as pectin and D-limonene and fermenting the remaining matter to produce ethanol (Edwards and Doran-Peterson 2012). However, due to the limited size of the world pectin market and the inability of ethanologenic yeasts to ferment D-galacturonic acid (Van Maris et al. 2006), the main constituent in pectin, it is possible to utilize only a part of CPW in these processes. Other proposed products from CPW include methane (López et al. 2010), citric acid (Rivas et al. 2008), succinic acid (Li et al. 2010a) and enzymes (López et al. 2010). In the current work, we open a new route to increase the value of CPW using engineered Aspergillus niger strains to convert the pectin to L-galactonic acid in a consolidated process.

L-Galactonic acid and its lactone (L-galactono-1,4-lactone) are currently expensive speciality chemicals and are not widely used. However, these compounds would have the potential to be used more widely if they were available at a lower price. L-Galactonic acid is also a precursor for Lascorbic acid (vitamin C): L-galactono-1,4-lactone, which is formed from L-galactonic acid upon acidification, can be directly converted to L-ascorbic acid through a fermentative process (Onofri et al. 1997, Roland et al. 1986) or through a chemical process (Csiba et al. 1993). The annual production of synthetic L-ascorbic acid is about 100000 tonnes (Pappenberger and Hohmann 2013). The 500000 tonnes of pectin in the annually produced CPW contains around 375000 tonnes of D-galacturonic acid. In turn, equimolar conversion of this $\mathrm{D}$-galacturonic acid to $\mathrm{L}$ galactonic acid and, subsequently, to L-ascorbic acid could be theoretically achieved. Therefore, even after factoring in conversion efficiencies below $100 \%$, CPW could easily supply the raw material for world L-ascorbic acid production. The production of polymers derived from L-galactonic acid has also been studied (Romero Zaliz and Varela 2003, Romero Zaliz and Varela 2005).

L-Galactonic acid is an intermediate of the reductive pathway for catabolism of D-galacturonate that is found in moulds such as Aspergillus niger (Figure 1) (Richard and Hilditch 2009). In A. niger, D-galacturonate is first reduced to L-galactonate by the D-galacturonate reductase, GAAA (Martens-Uzunova and Schaap 2008). L-Galactonate is subsequently converted to 2-keto-3-deoxy-L-galactonate (3-deoxy-L-threo-hex-2-ulosonate) by the L-galactonate dehydratase, GAAB, which is then further metabolized to pyruvate and glycerol by the action of GAAC and GAAD (Martens-Uzunova and Schaap 2008).

The deletion of the gene coding for the L-galactonate dehydratase, gaaB, resulted in a strain of $A$. niger that does not grow on D-galacturonic acid but instead converts Dgalacturonate to L-galactonate (Kuivanen et al. 2012). Since this strain produces pectinases, it was able to produce L-galactonate from polygalacturonate in a submerged fermentation (Kuivanen et al. 2012). The aim of the current work was to determine whether this strain could be used to hydrolyse the pectin in the CPW and convert the resulting D-galacturonic acid to L-galactonic acid in a single fermentation process.

\section{Materials and methods}

\section{Strains}

The Aspergillus niger strain ATCC 1015 (CBS 113.46) was used as a wild type. Engineered strains ATCC $1015 \Delta$ gaaB (L-galactonate dehydratase deletion strain) and $\triangle g a a B$ gaaA (L-galactonate dehydratase strain with overexpression of the D-galacturonate reductase $g a a A$ ) were described previously (Kuivanen et al. 2012). The strains $\triangle g a a B$ and $\triangle g a a B$-gaaA are deposited in VTT Culture Collection as D-121454 and D-121455, respectively.

\section{Preparation of the substrate}

Citrus processing waste $(\mathrm{CPW})$, remaining after the preparation of fresh orange juice, was obtained from a local restaurant in Curitiba (Brazil). The CPW was dried at $60^{\circ} \mathrm{C}$ and milled with a grinder to a particle size of 0.9-2.4 mm. The ground CPW was washed with water in order to remove soluble sugars and dried again at $60^{\circ} \mathrm{C}$. Finally, the powder was autoclaved for $40 \mathrm{~min}$ at $120^{\circ} \mathrm{C}$.

\section{Submerged fermentations}

For the submerged fermentations (SmF) with CPW, mycelia were pre-grown in 250-ml Erlenmeyer flasks in a medium containing (in $\mathrm{g}^{-1}$ ): yeast extract 10 , peptone 20 and gelatin 30. Pre-cultures were inoculated with a spore suspension and incubated overnight at $28^{\circ} \mathrm{C}, 200 \mathrm{rpm}$. Mycelia were harvested by vacuum filtration and rinsed with sterile water. Submerged cultures contained $40 \mathrm{~g} \mathrm{l}^{-1}$ of the prepared CPW, which, due to the residual water, represents $35.1 \mathrm{~g} \mathrm{l}^{-1}$ on a dry mass (DM) basis and were supplemented with $A$. nidulans defined minimal medium (Barratt et al. 1965), containing (in $\mathrm{g} \mathrm{l}^{-1}$ ): $\mathrm{NaNO}_{3} 6, \mathrm{KCl}$ $0.52, \mathrm{MgCl}_{2} 0.52$ and $\mathrm{KH}_{2} \mathrm{PO}_{4}$ 1.52. In a separate culture, only sterile water with $40 \mathrm{~g} \mathrm{l}^{-1}$ of the prepared CPW was used. Cultures were carried out in 250-ml Erlenmeyer flasks containing $50 \mathrm{ml}$ final volume and were inoculated 


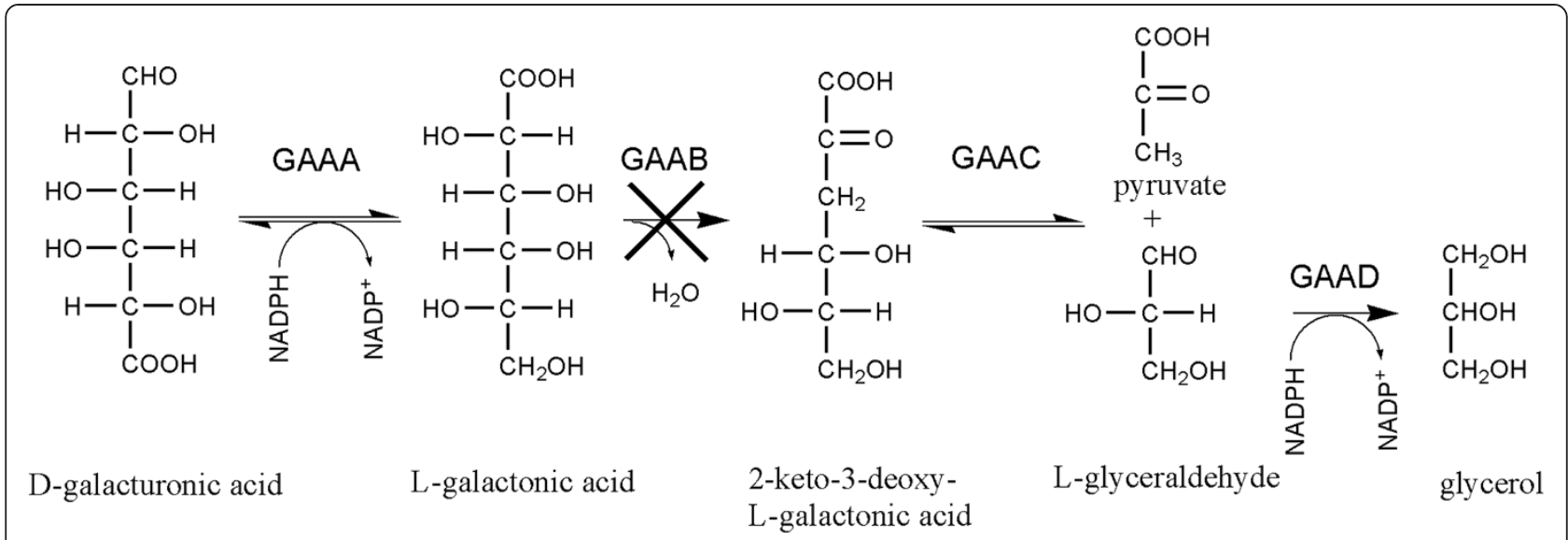

Figure 1 The catabolic D-galacturonic acid pathway in A. niger. The enzymes of this pathway are D-galacturonic acid reductase (GAAA), L-galactonate dehydratase (GAAB), 2-keto-3-deoxy-L-galactonate aldolase (GAAC) and L-glyceraldehyde reductase (GAAD). The strains used in the present work were engineered to have no GAAB activity.

with $10 \mathrm{~g} \mathrm{l}^{-1}\left(2.3 \mathrm{~g} \mathrm{l}^{-1} \mathrm{DM}\right)$ of pre-grown mycelia and incubated at $28^{\circ} \mathrm{C}$ and at $200 \mathrm{rpm}$. Samples were taken for HPLC analysis at intervals and solid matter (mycelia + insoluble substrate) was removed by centrifugation. In the fermentation for purification of the L-galactonic acid, $40 \mathrm{~g} \mathrm{l}^{-1}$ of the prepared CPW was fermented in $500 \mathrm{ml}$ of water in a $2000 \mathrm{ml}$ flask. The culture was inoculated and incubated as described above.

\section{Solid-state fermentations}

For the small scale solid-state fermentation (SSF) $2 \mathrm{~g}$ (1.76 g DM) of the CPW, prepared as described above, was added to each $100-\mathrm{ml}$ Erlenmeyer flask. Sterile water $(6 \mathrm{ml})$ containing inoculum of $2 \times 10^{7}$ spores was added. The flasks were incubated at $28^{\circ} \mathrm{C}$ and a relative humidity of $96 \%$. The effect of nutritional supplementation in SSF was studied by adding either $6 \mathrm{ml}$ of pure water or a solution containing (in $\mathrm{g} \mathrm{l}^{-1}$ ): $\mathrm{K}_{2} \mathrm{HPO}_{4} 3$, $\left(\mathrm{NH}_{4}\right)_{2} \mathrm{SO}_{4}$ 13, $\mathrm{MgSO}_{4} \cdot 7 \mathrm{H}_{2} \mathrm{O}$ 5, KCl 10 and FeS$\mathrm{O}_{4} .7 \mathrm{H}_{2} \mathrm{O} 0.1$.

In order to investigate the potential for scaling up the process, packed-bed bioreactors ( $28 \mathrm{~cm}$ by $3.5 \mathrm{~cm}, \sim 270 \mathrm{ml})$ were used. For each column, $10 \mathrm{~g}(8.78 \mathrm{~g} \mathrm{DM})$ of the prepared CPW was wetted with $30 \mathrm{ml}$ of the nutritional supplementation (as above) containing an inoculum $\left(10^{7}\right.$ spores per g prepared CPW). Columns were incubated in a water bath maintained at $28^{\circ} \mathrm{C}$. Each column received a flow rate of air (saturated with water at $28^{\circ} \mathrm{C}$ ) of $150 \mathrm{ml} \mathrm{min}$.

For the extraction of the fermentation products, $15 \mathrm{ml}$ of sterile water were added per $1 \mathrm{~g}(0.88 \mathrm{~g} \mathrm{DM})$ of fermented solids and the suspension was incubated at $28^{\circ} \mathrm{C}$ and $200 \mathrm{rpm}$ for an hour. The liquid was collected by vacuum filtration and analysed by HPLC.

\section{D-galacturonic acid content of the CPW}

In order to estimate the total D-galacturonic acid content in the substrate, $1 \mathrm{~g}(0.88 \mathrm{~g} \mathrm{DM})$ of the prepared CPW was hydrolysed with 127 PGNU (polygalacturonase unit, as defined by Novozymes) per $\mathrm{ml}$ of a commercial pectinase (Pectinex Ultra SP-L, Novozymes) in a final volume of $30 \mathrm{ml}$. The reaction mixture was incubated overnight at $30^{\circ} \mathrm{C}$ and at $100 \mathrm{rpm}$. The hydrolysed orange peel suspension was centrifuged and the supernatant was analysed by HPLC. The water content in the dried CPW was determined by heating the CPW in oven at $100^{\circ} \mathrm{C}$ overnight and weighing to determine the loss of mass.

\section{Transcriptional analysis}

For the transcriptional analysis in the submerged fermentations, $1 \mathrm{ml}$ samples were collected and the mycelia were harvested by vacuum filtration, frozen with liquid nitrogen and stored at $-80^{\circ} \mathrm{C}$. RNA was extracted with the RNeasy Plant Mini Kit (Qiagen) following the manufacturer's instructions.

cDNA was prepared using the First Strand cDNA Synthesis Kit (Roche) following the manufacturer's instructions. Quantitative PCR was carried out using the LightCycler SYBR green I master mix and the LightCycler 96 System. The transcription of putative D-galacturonate transporters An14g04280 and An03g01620 (Martens-Uzunova and Schaap 2008) was quantified with the primers listed previously (Kuivanen et al. 2012). The transcription levels were normalized to actin using the accompanying software (Advanced Relative Quantification Tool).

\section{L-galactonic acid purification}

After the $500-\mathrm{ml} \mathrm{SmF}$, the broth was separated by vacuum filtration and loaded onto an ion-exchange resin 
(Dowex 1X8, formate form). The bound L-galactonic acid was eluted with a linear formic acid gradient from 0 to $3 \mathrm{M}$. Fractions were collected and analysed by HPLC. The fractions with the highest L-galactonic acid content were combined and lyophilized. The resulting powder was dissolved in water and the proportions of linear L-galactonic acid and L-galactono-1,4-lactone were quantified using the colorimetric lactone assay (Hestrin 1949). In the assay, $200 \mu \mathrm{l}$ of the dissolved product was mixed with $400 \mu \mathrm{l}$ of solution containing $4 \mathrm{M}$ hydroxylamine and $4 \mathrm{M} \mathrm{NaOH}$, followed by acidification with $200 \mu \mathrm{l}$ of $4 \mathrm{M} \mathrm{HCl}$ and addition of $200 \mu \mathrm{l}$ of $100 \mathrm{~g} \mathrm{l}^{-1} \mathrm{FeCl}_{3}$ in $0.1 \mathrm{M} \mathrm{HCl}$. The absorbance was measured at $540 \mathrm{~nm}$. Commercial L-galactono-1,4-lactone (Sigma) was used for the standard curve.

In an alternative procedure, the suitability of calcium precipitation for the purification was studied, using a method similar to that described for succinate (Li et al. $2010 b)$. In order to remove some of the impurities and clarify the broth, filtered final broth was stirred with activated carbon $(12.5 \% \mathrm{w} / \mathrm{v})$ for an hour. The activated carbon was then removed by filtration and the resulting clear liquid was collected. In order to precipitate the product as calcium L-galactonate, the liquid was stirred and solid $\mathrm{Ca}(\mathrm{OH})_{2}$ was added until the $\mathrm{pH}$ rose to 12.6. The resulting precipitate was collected by filtration and rinsed with cold water. L-Galactonic acid was released from the calcium salt by adding $0.5 \mathrm{M} \mathrm{H}_{2} \mathrm{SO}_{4}$ until $\mathrm{pH}$ 2.0. The precipitate $\left(\mathrm{CaSO}_{4}\right)$ was removed by filtration and the filtrate was analysed by HPLC.

\section{HPLC analysis and calculations}

The concentrations of sugars and sugar acids were determined by HPLC, using a fast acid analysis column (100 by $7.8 \mathrm{~mm}$, Bio-Rad laboratories, Hercules, CA) linked to an Animex HPX-87H organic acid analysis column (300 by $7.8 \mathrm{~mm}$, Bio-Rad Laboratories), with $5 \mathrm{mM}$ $\mathrm{H}_{2} \mathrm{SO}_{4}$ as the eluent and a flow rate of $0.5 \mathrm{ml} \mathrm{min}{ }^{-1}$. The column was maintained at $55^{\circ} \mathrm{C}$. Peaks were detected with a Waters 410 differential refractometer.

All the sugar and sugar acid contents, the product yields and production rates were calculated on the basis of the DM of CPW used. Margins of error are presented as standard errors of the means (SEM). All the statistical tests were carried out using Student's t-test. In the Table 1, the "product yield" is calculated from the highest Lgalactonic acid concentration during the fermentation (Figures 2A and 3A). The "product yield of theoretical maximum" represents the ratio of the highest L-galactonic acid content (in the fermentation) to the D-galacturonic acid content in the CPW (determined as described above).

\section{Results}

In order to investigate the conversion of CPW to Lgalactonic acid, we inoculated ground CPW with wild type and engineered $A$. niger strains ( $\triangle$ gaaB and $\triangle g a a B$ gaaA) and tested solid-state (SSF) and submerged (SmF) fermentations. A key value-added by-product from CPW is D-limonene, which is inhibitory for many microbes (Pourbafrani et al. 2010), including A. niger (Sharma and Tripathi 2008). In our process, it was not specifically extracted, although the washing of CPW possibly decreased its D-limonene content. The inhibitory effect of D-limonene was not studied in the process. After the washing, the insoluble material, containing mainly pectin, cellulose and hemicellulose, was fermented in SmF and SSF processes. The D-galacturonic acid resulting from the pectin hydrolysis was reduced to L-galactonic acid by the $\triangle g a a B$ and $\triangle g a a B$-gaaA strains. LGalactonic acid production was not observed in either process using the wild type strain.

\section{Composition of CPW}

The content of D-galacturonic acid in the substrate was analysed by hydrolysing the prepared CPW with pectinases. The D-galacturonic acid was quantified by HPLC. This allowed calculation of the maximal theoretical yield of L-galactonic acid that can be obtained from CPW (1 mol of L-galactonic acid per $1 \mathrm{~mol}$ of Dgalacturonic acid). The water content in the prepared dry CPW substrate was $12.2 \pm 0.4 \%$. In the remaining matter, the content of free D-galacturonic acid was $270 \pm 7 \mathrm{mg}$ per $\mathrm{g}$ CPW (on a DM basis) after pectinase hydrolysis. The other main soluble components in the hydrolysed CPW were, in mg per g CPW, D-glucose $55 \pm 1$, D-galactose $62 \pm 1$, Larabinose $67 \pm 2$ and L-rhamnose $15 \pm 1$. The soluble sugars and sugar acids released in the pectinase hydrolysis accounted for $46.6 \%$ of the dry mass of the CPW.

\section{Consolidated conversion of orange peel to L-galactonic acid in submerged fermentation}

In SmF, supplementation with the mineral salt solution improved both the initial productivity and the final yield of Lgalactonic acid for both $\triangle g a a B$ and $\triangle g a a B$-gaaA (Table 1 and Figure $2 \mathrm{~A})$. The initial productivity increased from values of $0.74-1.01 \mathrm{mg} \mathrm{g}^{-1} \mathrm{~h}^{-1}$ to around $1.2 \mathrm{mg} \mathrm{g}^{-1} \mathrm{~h}^{-1}$ and the product yield increased from values of $79-95 \mathrm{mg} \mathrm{g}^{-1}$ to around $160 \mathrm{mg} \mathrm{g}^{-1}$. The highest L-galactonic acid titer among SmFs, $5.60 \pm 0.09 \mathrm{~g} \mathrm{l}^{-1}$ (after $119 \mathrm{~h}$ ), was obtained with $\triangle g a a B-g a a A$ in the supplemented process (Figure 2A). The $\mathrm{pH}$ during the fermentation was lower in SmFs without supplementation (Figure 2B). Although low pH increased L-galactonic acid production in SmF in a previous study (Kuivanen et al. 2012), the value below 2 that was reached in the current study might have had a negative effect.

In order to investigate the transport of the substrate into the cell, the transcription of two putative D-galacturonic acid transporters, An14g04280 and An03g01620, was 
Table 1 Initial productivities, product yields and product yields as a percentage of the theoretical maximum from SmFs and SSFs on a DM basis

\begin{tabular}{|c|c|c|c|c|c|c|}
\hline \multirow[t]{2}{*}{ Strain } & \multicolumn{2}{|c|}{$\begin{array}{l}\text { Initial productivity } \\
\mathrm{mg}_{\mathrm{L-galactonate}} / \mathrm{g}_{\text {peel }} / \mathrm{h}\end{array}$} & \multicolumn{2}{|c|}{$\begin{array}{l}\text { Product yield, } \mathrm{Y}_{\mathrm{p} / \mathrm{s}} \\
\mathrm{mg}_{\mathrm{L}-\text { galactonate }} / \mathrm{g}_{\text {peel }}\end{array}$} & \multicolumn{2}{|c|}{$\begin{array}{l}\text { Product yield (\%) of theoretical maximum } \\
\text { gL-galactonate/g }_{\text {D-galacturonate }}\end{array}$} \\
\hline & SmF & SSF & SmF & SSF & $\mathrm{SmF}$ & SSF \\
\hline & $0-70.5 \pm 1.5 h$ & $0-96 \mathrm{~h}$ & & & & \\
\hline$\Delta g a a B$ (without suppl.) & $1.01 \pm 0.04^{c}$ & $0.35 \pm 0.01$ & $79 \pm 5$ & $116 \pm 2^{c}$ & $23 \%$ & $43 \%$ \\
\hline$\Delta g a a B-g a a A$ (without suppl.) & $0.74 \pm 0.03^{c}$ & $0.49 \pm 0.02$ & $95 \pm 3$ & $167 \pm 2^{c}$ & $35 \%$ & $62 \%$ \\
\hline$\Delta g a a B$ (with suppl.) & $1.16 \pm 0.01$ & $d_{2.14} \pm 0.09$ & $157 \pm 3$ & ${ }^{d} 233 \pm 2^{c}$ & $58 \%$ & $87 \%$ \\
\hline$\Delta g a a B-g a a A$ (with suppl.) & $1.26 \pm 0.02$ & ${ }^{d} 2.35 \pm 0.03^{c}$ & $159 \pm 3$ & ${ }^{d} 221 \pm 6^{c}$ & $59 \%$ & $82 \%$ \\
\hline
\end{tabular}

${ }^{c}$ The process type $(\mathrm{SmF}$ or SFF) significantly $(\mathrm{p}<0.05)$ better than the other in the same nutritional conditions.

${ }^{d}$ Errors present \pm SEM, $\mathrm{n}=2$.

Errors represent $\pm S E M, n=3$.
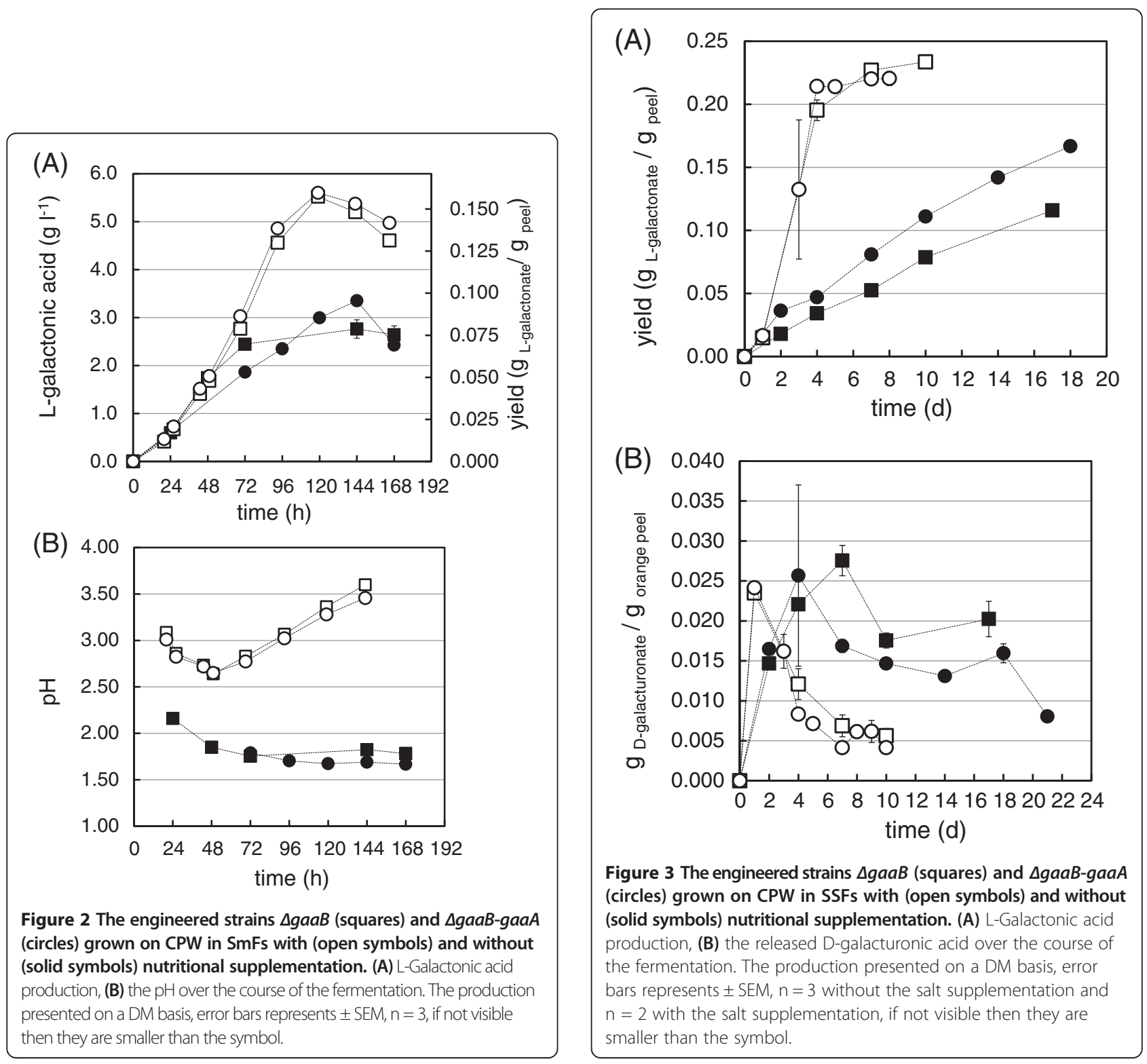
followed by qPCR in the SmFs carried out with $\triangle$ gaaB without the nutritional supplementation (Figure 4). The transcription of An14g04280 in $\triangle g a a B$ did not show any induction on CPW, whereas the transcription of An03g01620 was clearly induced.

\section{Consolidated conversion of orange peel to L-galactonic acid in solid-state fermentation}

As with SmF, in SSF supplementation with the mineral salts solution improved both the initial productivity and the final yield of L-galactonic acid for both $\triangle g a a B$ and $\triangle$ gaaB-gaaA (Table 1 and Figure $3 \mathrm{~A}$ ). The initial productivity increased from values of $0.35-0.49 \mathrm{mg} \mathrm{g}^{-1} \mathrm{~h}^{-1}$ to values of 2.14-2.35 $\mathrm{mg} \mathrm{g}^{-1} \mathrm{~h}^{-1}$ and the product yield increased from values of $116-167 \mathrm{mg} \mathrm{g}^{-1}$ to values $220-$ $230 \mathrm{mg} \mathrm{g}^{-1}$. In the SSFs, the D-galacturonic acid profiles were also determined (Figure $3 \mathrm{~B}$ ). The rates of release and consumption of D-galacturonic acid were both faster in the supplemented SSF. In addition, both of the engineered strains produced lower D-galacturonic acid concentrations during the fermentation when compared to the wild type (wild type data not shown).

In large-scale SSF processes, packed-bed bioreactors are often used since they are less labour-intensive than tray-type processes (such as that undertaken in the current work in the Erlenmeyer flasks). In order to assess the performance of the process in this type of bioreactor, glass columns were loaded with $10 \mathrm{~g}$ (8.78 g $\mathrm{DM}$ ) of CPW and the nutritional supplementation was used. The product yields were slightly lower than those in flask-scale SSFs: after 4 days, the L-galactonic acid yields obtained with $\triangle g a a B$ and $\triangle g a a B-g a a A$ were 166

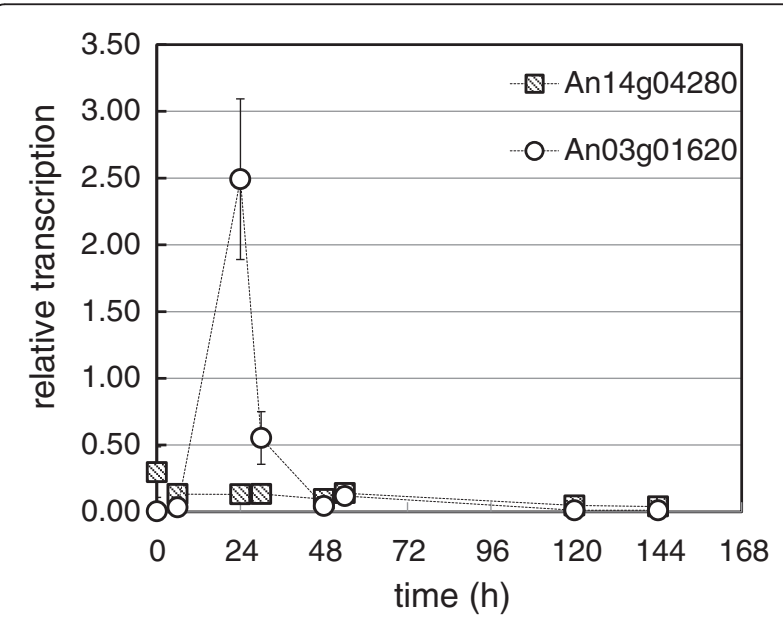

Figure 4 Transcription of the putative D-galacturonate transporters An14g04280 and An03g01620 in $\triangle$ gaaB strain over the course of the SmF on CPW. The transcription levels are presented as relative to the transcription of actin. Error bars represents $\pm S E M, n=3$, at $24 \mathrm{~h}$ for An03g01620 $n=2$, if not visible then they are smaller than the symbol. and $153 \mathrm{mg} \mathrm{g}^{-1}$, respectively, corresponding to 61 and $57 \%$, respectively, of the theoretical maximum yields.

\section{Purification and applications of L-galactonic acid}

L-Galactonic acid produced from CPW in a 500-ml SmF was purified using a Dowex resin and lyophilisation. Seventeen percent of the L-galactonic acid in the fermentation broth was recovered. In this purified product, $69 \%$ of the Lgalactonic acid was in the linear form, whereas $31 \%$ was present as L-galactono-1,4-lactone. The alternative method for L-galactonic acid purification involved treatment of the fermentation broth with activated carbon then precipitation of L-galactonic acid as a calcium carboxylate salt. After treatment of the salt with sulphuric acid, the final liquid contained $20 \%$ of the initial L-galactonic acid.

\section{Discussion}

There are several previous reports that describe processes converting pectin-rich biomass to ethanol using Saccharomyces cerevisiae or Escherichia coli (Edwards and DoranPeterson 2012). Due to the inability of these organisms to hydrolyse pectin and cellulose, additional pectinolytic and cellulolytic enzymes are required. From that perspective, it is an advantage to use a production organism, such as $A$. niger, that is naturally capable of hydrolysing pectin and cellulose: this enables a consolidated bioprocess. In the current work, we established a new consolidated bioprocess converting CPW to L-galactonic acid.

In the present study, the volumetric titers of L-galactonic acid after $72 \mathrm{~h}$ in the supplemented SmFs with $\triangle g a a B$ and $\triangle$ gaaB-gaaA were around $3 \mathrm{~g} \mathrm{l}^{-1}$ resulting in an approximate volumetric productivity of $42 \mathrm{mg} \mathrm{l}^{-1} \mathrm{~h}^{-1}$ (Figure 2A). This value is relatively close to the initial productivities of 46-64 and 54-70 $\mathrm{mg} \mathrm{l}^{-1} \mathrm{~h}^{-1}$ that were obtained with $\triangle g a a B$ and $\triangle g a a B$-gaaA, respectively, in SmF of a defined medium supplemented with $10 \mathrm{~g} \mathrm{l}^{-1}$ of D-galacturonic acid and $2 \mathrm{~g} \mathrm{l}^{-1}$ of D-xylose (Kuivanen et al. 2012). The product yields (\% of theoretical maximum, i.e. g L-galactonic acid per $g$ initial D-galacturonic acid) obtained in the defined conditions were 47 and 59\% with $\triangle g a a B$ and $\triangle g a a B$-gaaA, respectively (Kuivanen et al. 2012). The corresponding values in this study were similar, being 58 and 59\% respectively (Table 1). However, the L-galactonic acid yields, 87 and $82 \%$ of the theoretical maximum, obtained in SSF with $\triangle g a a B$ and $\triangle g a a B-g a a A$, respectively, in the current study, were clearly higher when compared to those of the SmFs (Table 1). The SSFs in packed-bed column bioreactors resulted in yields close to those of achieved in SmF. However, the longest bioreactor fermentation was extracted after 4 days, which may be too short a time for the optimal yield.

The higher product yields in the SSFs might be due to a difference in pectin hydrolysis under submerged and solid-state conditions. In fact, the presence of free sugars, such as D-glucose or sucrose, strongly decreases the 
production of endo- and exo-pectinases by $A$. niger in SmF, but not in SSF, which indicates a possible difference in the regulation of pectin metabolism between submerged and solid-state conditions (Solis-Pereira et al. 1993). This is most likely due to the concentration gradients that arise, with the concentrations of soluble sugars remaining low in the vicinity of the hyphae and therefore not causing catabolite repression (Viniegra-González and Favela-Torres 2006).

Small amounts of D-galacturonic acid were still present in the SSFs after the L-galactonic acid production had slowed significantly (compare profiles in Figure $3 \mathrm{~A}$ and $\mathrm{B}$ over the period of 72-216 h). In contrast, no D-galacturonic acid was found at the end of the SmFs (i.e. after $120 \mathrm{~h}$, data not shown), even though the yields of L-galactonic acid were only $23-59 \%$ of the theoretical maximum values (Table 1 ). There are two possible explanations for the final product yields being below 100\%: pectin hydrolysis may have been incomplete or some of the L-galactonic acid that was produced may have been consumed. The strain $\triangle$ gaaB was unable to catabolize L-galactonic acid in submerged cultures when pure D-galacturonic acid or polygalacturonate were used (Kuivanen et al. 2012). However, several additional carbon sources are present in the CPW and might induce expression of unspecific dehydratases, allowing some L-galactonic acid consumption, since the genome of $A$. niger contains at least four putative dehydratase coding genes in addition to gaaB. A similar kind of phenomenon was described in an engineered $A$. niger strain with a disturbed D-galacturonate pathway (a deletion of D-galacturonate reductase, gaaA) and an introduced uronic acid dehydrogenase: The resulting strain was able to utilize D-galacturonate through an unknown pathway (Mojzita et al. 2010).

The transcription of two putative $\mathrm{D}$-galacturonate transporters An14g04280 and An03g01620 was followed during the SmF without the nutritional supplementation (Figure 4). These transporters have a strong similarity to hexose transporters and their transcription is induced in wild type $A$. niger when cultured on D-galacturonate, polygalacturonate and sugar beet pectin (Kuivanen et al. 2012, Martens-Uzunova and Schaap 2008). In the present study, only induction of An03g01620 was observed. This transcriptional pattern is similar to that obtained when A. niger $\triangle$ gaaB was cultivated on a mixture of pure Dgalacturonic acid and D-xylose (Kuivanen et al. 2012). The reason for altered expression of An14g04280 in $\triangle g a a B$ remains unclear, however, it may have a negative effect on the D-galacturonic acid transport into the cell. The peak of the An03g01620 induction during growth on CPW occurred in the current work at $24 \mathrm{~h}$ whereas the corresponding peak on pure D-galacturonic acid was at $3 \mathrm{~h}$ (Kuivanen et al. 2012). The time difference is most likely due to the inhibitory effect of other sugars of the CPW on pectin hydrolysis and D-galacturonic acid catabolism at the beginning of the SmF.

In the context of L-ascorbic acid (vitamin C) synthesis, it is advantageous to know whether the product from the consolidated process is linear L-galactonic acid or Lgalactono-1,4-lactone: a single reduction step is required to form L-ascorbic acid from the lactone, whereas the linear form would need to be first lactonized. The L-galactonic acid recovered from the Dowex resin was a mixture of linear and lactonized form. The lactonization of L-galactonic acid is thermodynamically more favourable at low $\mathrm{pH}$, thus the elution with formic acid probably caused the partial lactonization. We also tested the suitability of calcium precipitation for the L-galactonic acid recovery because it is widely used in the industry. The purification yield remained relatively low (20\%) since the process was not optimized for Lgalactonic acid. However, this method, once optimized, could potentially be used for L-galactonic acid recovery.

Currently, industrial production of L-ascorbic acid begins with D-sorbitol, which is produced by the hydrogenation of D-glucose derived from corn or wheat (Bremus et al. 2006). The predominant manufacturing methods are still based on Reichstein process, which is a chemical process (Reichstein and Grüssner 1934). Current processes, that also involve fermentation steps, are still energy intensive (Bremus et al. 2006) and use valuable D-glucose as a raw material. From that perspective, a production method utilizing a single fermentation step and low value CPW as the raw material would be highly desirable.

In the present work, L-galactonic acid was produced from CPW in a consolidated process by engineered $A$. niger strains. Close to $90 \%$ product yield was achieved, based on the D-galacturonic acid contained in the pectin of the CPW. To the best of our knowledge, this is the first report on a consolidated bioprocess in which a pectin-rich residue is converted to a high value biochemical using an engineered microorganism.

\section{Competing interests}

The authors declare that they have no competing interests.

\section{Acknowledgements}

This study was supported by the Academy of Finland through the Sustainable Energy (SusEn) program (grant 271025) and by CNPq (Conselho Nacional de Desenvolvimento Científico e Tecnológico), a Brazilian government agency for the advancement of science, in the form of a cooperation project. Edgar Mallmann, Alessandra Biz, Nadia Krieger and David Mitchell also thank CNPq for research scholarships. The authors declare that they have no competing interest.

\section{Author details}

${ }^{1}$ VTT Technical Research Centre of Finland, PO Box 1000, 02044 VTT, Espoo, Finland. ${ }^{2}$ Department of Biochemistry and Molecular Biology, Federal University of Paraná, P.O. Box 19046, 81531-990 Curitiba-PR, Brazil.

Received: 29 January 2014 Accepted: 2 February 2014

Published: 18 March 2014 


\section{References}

Barratt RW, Johnson GB, Ogata WN (1965) Wild-type and mutant stocks of Aspergillus nidulans. Genetics 52:233-246

Bremus C, Herrmann U, Bringer-Meyer S, Sahm H (2006) The use of microorganisms in L-ascorbic acid production. J Biotechnol 124:196-205

Csiba M, Cleophax J, Petit S, Gero S (1993) An expedient and practical three-step synthesis of vitamin C from a byproduct of the sugar industry: the L-galactono-1, 4-lactone pathway. J Org Chem 58:7281-7282

Edwards MC, Doran-Peterson J (2012) Pectin-rich biomass as feedstock for fuel ethanol production. Appl Microbiol Biotechnol 95:565-575

Grohman K, Cameron R, Kim Y, Widmer W, Luzio G (2013) Extraction and recovery of pectic fragments from citrus processing waste for co-production with ethanol. J Chem Technol Biotechnol 88:395-407

Hestrin S (1949) The reaction of acetylcholine and other carboxylic acid derivatives with hydroxylamine, and its analytical application. J Biol Chem 180:249-261

Kuivanen J, Mojzita D, Wang Y, Hilditch S, Penttilä M, Richard P, Wiebe MG (2012) Engineering filamentous fungi for conversion of D-galacturonic acid to L-galactonic acid. Appl Environ Microbiol 78:8676-8683

Li Q, Siles JA, Thompson IP (2010a) Succinic acid production from orange peel and wheat straw by batch fermentations of Fibrobacter succinogenes $\mathbf{5 8 5}$. Appl Microbiol Biotechnol 88:671-678

Li Q, Wang D, Wu Y, Li W, Zhang Y, Xing J, Su Z (2010b) One step recovery of succinic acid from fermentation broths by crystallization. Sep Purif Technol 72:294-300

López J, Li Q, Thompson I (2010) Biorefinery of waste orange peel. Crit Rev Biotechnol 30:63-69

Martens-Uzunova ES, Schaap PJ (2008) An evolutionary conserved D-galacturonic acid metabolic pathway operates across filamentous fungi capable of pectin degradation. Fungal Genet Biol 45:1449-1457

Mojzita D, Wiebe M, Hilditch S, Boer H, Penttilä M, Richard P (2010) Metabolic engineering of fungal strains for conversion of D-galacturonate to meso-galactarate. Appl Environ Microbiol 76:169-175

Onofri S, Poerio E, Serangeli P, Tosi S, Garuccio I, Arrigoni O (1997) Influence of $\mathrm{L}$-galactonic acid $\mathrm{\gamma}$-lactone on ascorbate production in some yeasts. Antonie Van Leeuwenhoek 71:277-280

Pappenberger G, Hohmann H (2013) Industrial Production of L-Ascorbic Acid (Vitamin C) and D-Isoascorbic Acid. Adv Biochem Eng Biotechnol. DOl: 10.1007/ 10_2013_243

Pourbafrani M, Forgács G, Horváth IS, Niklasson C, Taherzadeh MJ (2010) Production of biofuels, limonene and pectin from citrus wastes. Bioresour Technol 101:4246-4250

Reichstein T, Grüssner A (1934) Eine ergiebige synthese der L-ascorbinsäure (C-vitamin). Helv Chim Acta 17:311-328

Richard P, Hilditch S (2009) D-galacturonic acid catabolism in microorganisms and its biotechnological relevance. Appl Microbiol Biotechnol 82:597-604

Rivas B, Torrado A, Torre P, Converti A, Domínguez JM (2008) Submerged citric acid fermentation on orange peel autohydrolysate. J Agric Food Chem 56:2380-2387

Roland JF, Cayle T, Dinwoodie RC, Mehnert DW (1986) Fermentation production of ascorbic acid from L-galactonic substrate. US Patent, USA, 4,595,659, 17 June 1986

Romero Zaliz CL, Varela O (2003) Straightforward synthesis of derivatives of D-and L-galactonic acids as precursors of stereoregular polymers. Tetrahedron Asymmetry 14:2579-2586

Romero Zaliz CL, Varela O (2005) Synthesis of stereoregular poly-O-methyl-D- and L-polygalactonamides as nylon 6 analogues. Tetrahedron Asymmetry 16:97-103

Sharma N, Tripathi A (2008) Effects of Citrus sinensis (L.) Osbeck epicarp essential oil on growth and morphogenesis of Aspergillus niger (L.) Van Tieghem. Microbiol Res 163:337-344

Solis-Pereira S, Favela-Torres E, Viniegra-González G, Gutiérrez-Rojas M (1993) Effects of different carbon sources on the synthesis of pectinase by Aspergillus niger in submerged and solid state fermentations. Appl Microbiol Biotechnol 39:36-41

Staunstrup J (2009) Citrus pectin production and world market. Paper presented at 49 th annual short course for the food industry. The International Citrus \& Beverage Conference, Clear Water Beach, Florida, 17 Sept 2009

USDA (2013) (United States Department of Agriculture). Citrus: World markets and trade 8. http://www.fas.usda.gov/psdonline/circulars/citrus.pdf. Accessed 5 Dec 2013

Van Maris AJA, Abbott DA, Bellissimi E, Brink J, Kuyper M, Luttik MAH, Wisselink HW, Scheffers WA, Dijken JP, Pronk JT (2006) Alcoholic fermentation of carbon sources in biomass hydrolysates by Saccharomyces cerevisiae: current status. Antonie Van Leeuwenhoek. Int J Gen Mol Microbiol 90:391-418

Viniegra-González G, Favela-Torres E (2006) Why solid-state fermentation seems to be resistant to catabolite repression? Food Technol Biotechnol 44:397

Widmer W, Zhou W, Grohmann K (2010) Pretreatment effects on orange processing waste for making ethanol by simultaneous saccharification and fermentation. Bioresour Technol 101:5242-5249

doi:10.1186/s13568-014-0033-z

Cite this article as: Kuivanen et al: Conversion of orange peel to L-galactonic acid in a consolidated process using engineered strains of Aspergillus niger. AMB Express 2014 4:33.

\section{Submit your manuscript to a SpringerOpen ${ }^{\mathcal{D}}$ journal and benefit from:}

- Convenient online submission

- Rigorous peer review

- Immediate publication on acceptance

- Open access: articles freely available online

- High visibility within the field

- Retaining the copyright to your article

Submit your next manuscript at $>$ springeropen.com 